\title{
Prevalence in the General Population of a CFH Sequence Variant Associated with Atypical Haemolytic Uraemic Syndrome in an Extensive Family from Southwest England
}

\author{
Alexander J. Hamilton $^{\mathrm{a}, \mathrm{b}}$ Carl B.A. Lyons ${ }^{\mathrm{c}}$ Timothy H.J. Goodship ${ }^{\mathrm{d}}$ \\ Coralie Bingham ${ }^{b}$ \\ ${ }^{a}$ NIHR Exeter Clinical Research Facility, University of Exeter Medical School, and ${ }^{b}$ Renal \\ Unit, Royal Devon and Exeter Hospital, Exeter, ${ }^{C}$ Department of Cellular and Anatomical \\ Pathology, Plymouth Hospitals NHS Trust, Plymouth, and ${ }^{d}$ Institute of Genetic Medicine, \\ Newcastle University, Newcastle upon Tyne, UK
}

\section{Key Words}

Atypical haemolytic uraemic syndrome $\cdot \mathrm{CFH} \cdot$ Thrombotic microangiopathy ·

Transplantation

\section{Abstract}

Background/Aims: Twenty-five members of a family from the county of Devon in England have been affected by atypical haemolytic uraemic syndrome (aHUS) associated with a CFH mutation (c.3643C>G; p.Arg1215Gly). A 65-year-old male was diagnosed with aHUS after losing a renal transplant to a thrombotic microangiopathy. Subsequent mutation screening revealed the same $\mathrm{CFH}$ mutation without him being knowingly related to the local kindred. We designed a study to investigate the prevalence of this mutation in the local area. In addition, we examined the diagnoses of pre-existing haemodialysis patients to determine whether other patients might unknowingly be at risk of carrying the same CFH mutation. Methods: The Exeter Ten Thousand (EXTEND) study aims to recruit 10,000 healthy volunteers over the age of 18 years living within 25 miles of Exeter in Devon. We genotyped DNA from 4,000 EXTEND subjects for CFH c.3643C>G; p.Arg1215Gly. We reviewed the diagnoses of 294 haemodialysis patients in the Devon area and genotyped 7 patients with either end-stage renal disease of unknown aetiology, malignant hypertension or renovascular disease. Results: CFH c.3643C>G; p.Arg1215Gly was not detected in any of the 7 haemodialysis patients or the 4,000 individuals within the EXTEND study. Conclusions: We conclude that CFH c.3643C>G; p.Arg1215Gly is not endemic in Devon. This reinforces our existing practice of genotyping only patients with kidney disease and evidence of a thrombotic microangiopathy for this mutation. This is the first study looking at the prevalence of $\mathrm{CFH}$ mutations in the general population. 
Hamilton et al.: Prevalence in the General Population of a CFH Sequence Variant Associated with aHUS in an Extensive Family from Southwest England

\section{Introduction}

Twenty-five members of a large family residing in the county of Devon in the southwest of England have been affected by atypical haemolytic uraemic syndrome (aHUS). This family was first described in 1978 by Edelsten and Tuck [1]. At that time, there were 4 affected individuals. Subsequently, in 1998, Warwicker et al. [2] established linkage to the regulators of complement activation (RCA) cluster of genes at chromosome 1q32 in 3 families including this one. One of the genes in this cluster is $\mathrm{CFH}$, which encodes the soluble complement regulator factor $\mathrm{H}$. In all the affected individuals (7 in total) from the Exeter region, Warwicker et al. [2] found a mutation in $C F H$ (c.3643C>G; p.Arg1215Gly). Since 1998, a further 18 individuals in this family have been affected and 18 unaffected carriers have been identified. The same mutation has also been identified in families residing in Wales and the Midlands. In both these families, there is strong evidence to suggest that they share a lineage in common with the family residing in the southwest of England. Since 1998, it has been shown that $\mathrm{CFH}$ mutations are the most frequent genetic abnormality in patients with aHUS, accounting for approximately $30 \%$ of cases [3]. The mutations are usually heterozygous and cluster in the C-terminal recognition domain of factor $\mathrm{H}$ [4]. Most result in a secreted mutant protein with impaired ability to regulate complement activation at cell surfaces. Progression to end-stage renal failure is rapid and recurrence rates after transplantation are high [5]. The mutations can present in childhood or adulthood with incomplete penetrance [6]. The high number of affected and unaffected individuals carrying CFH c.3643C $>$ G; p.Arg1215Gly in a family in a localised vicinity led us to examine whether other dialysis patients within the same vicinity might carry the same change and also whether the change might be detectable in the 'healthy' local population.

\section{Methods and Results}

\section{Case History}

In 2009, a 65-year-old male presented with malignant hypertension and acute kidney injury, having recently been started on an ACE inhibitor. A diagnosis of renovascular disease was made, and he did not recover renal function. He commenced regular haemodialysis and, 1 year later, received a live related kidney transplant from his son. Despite initial graft function, he rapidly lost the graft due to biopsy-proven thrombotic microangiopathy (TMA) (fig. 1). Subsequent mutation screening revealed that he carried $C F H$ c. 3643C $>$ G; p.Arg1215Gly without him being knowingly related to the local kindred. His son was found not to carry the mutation.

\section{CFH Screening in Haemodialysis Patients}

This case led us to examine the hypothesis that other patients undergoing haemodialysis in our unit might unknowingly carry this mutation. We reviewed the primary renal diagnoses of 294 haemodialysis patients in the Devon area. Using the inclusion/exclusion criteria shown in table 1, we undertook $C F H$ mutation screening in 7 patients as described previously [7]. Clinical information for these patients is given in table 2 . None of them were found to carry CFH c.3643C>G; p.Arg1215Gly.

\section{Prevalence of CFH c.3643C >G; p.Arg1215Gly in the Local Population}

This case also led us to examine the hypothesis that $C F H$ c.3643C $>$ G; p.Arg1215Gly is endemic in the local population. We used the Exeter Ten Thousand (EXTEND; www. exeter10000.org) study to address this hypothesis. This study aims to recruit 10,000 healthy volunteers over the age of 18 years living within 25 miles of Exeter (the principle town in the 


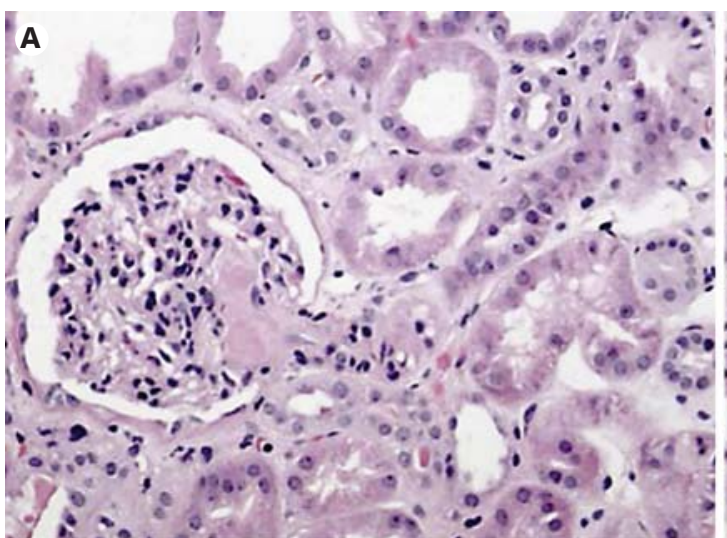

Hamilton et al.: Prevalence in the General Population of a CFH Sequence Variant Associated with aHUS in an Extensive Family from Southwest England
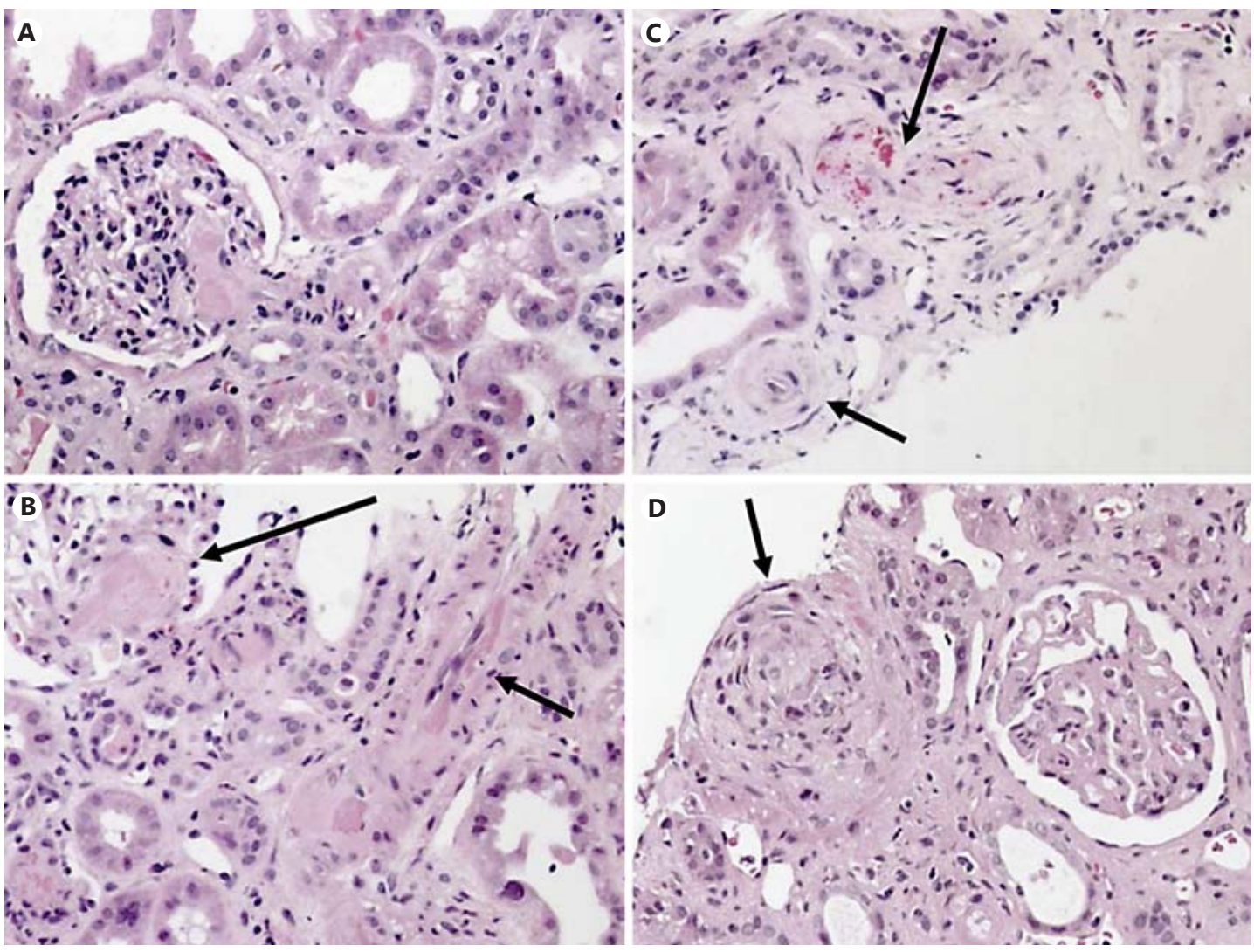

Fig. 1. Progressive TMA changes over subsequent renal transplant biopsies. A A relatively 'bloodless' glomerulus containing small hilar thrombi in the first biopsy. B Second biopsy with the glomerulus (long arrow) showing segmental thrombosis and subtle erythrocyte fragmentation. An arteriole cut longitudinally (short arrow) shows endothelial cell swelling and intimal expansion by myxoid/fibrinoid-necrotic material. C Second biopsy with the arteriole (long arrow) showing luminal obliteration by fibro-myxoid intimal thickening and erythrocyte extravasation and fragmentation. The arteriole (short arrow) shows a swollen endothelium and marked myxoid subendothelial thickening, compromising the lumen. D Third biopsy showing chronic TMA changes in the form of a 'glomeruloid body' (arrow) produced by proliferating endothelial cells, myocytes and myofibroblasts within an arteriole/small interlobular artery in response to injury, and prominent ischaemic glomerular and tubulointerstitial changes.

Table 1. Inclusion and exclusion criteria for haemodialysis patients

Inclusion criteria Diagnoses of malignant hypertension, unknown aetiology, chronic glomerulonephritis (never biopsied) or renovascular disease 3 generations from Devon

Exclusion criteria Another biopsy-proven diagnosis, adult polycystic kidney disease, nephrectomy, obstructive uropathy, diabetes, reflux nephropathy, drug-related causes Patient moved to Devon

vicinity of the family). To date, 4,000 individuals have entered the study. Each recruit consents for blood samples to be taken and used for a variety of purposes including genetic studies. The EXTEND steering committee approved access to 4,000 DNA samples for genotyping. None were found to carry $C F H$ c.3643C >G; p.Arg1215Gly. 
Hamilton et al:: Prevalence in the General Population of a CFH Sequence Variant

Associated with aHUS in an Extensive Family from Southwest England

Table 2. Haemodialysis patients tested for CFH c.3643C>G; p.Arg1215Gly mutation

\begin{tabular}{|c|c|c|c|c|c|c|c|c|}
\hline Patient & Age & Diagnosis & Renal biopsy & Ultrasound & $\mathrm{Hb}$ & Platelets & LDH & Blood film \\
\hline 1 & 76 & Unknown & No & Small kidneys & 8.4 & 243 & & \\
\hline 2 & 54 & $\begin{array}{l}\text { Hypertensive } \\
\text { nephropathy }\end{array}$ & No & $\begin{array}{l}\mathrm{L} 10.2 \mathrm{~cm} \\
\text { R } 10.7 \mathrm{~cm} \text {, simple cyst at } \\
\text { upper pole }\end{array}$ & 7.4 & 337 & 638 & \\
\hline 3 & 71 & $\begin{array}{l}\text { Hypertensive } \\
\text { nephropathy }\end{array}$ & Inconclusive & $\begin{array}{l}\text { L } 10.9 \mathrm{~cm} \text {, small cortical cyst } \\
\text { R } 10.4 \mathrm{~cm}\end{array}$ & 14.6 & 294 & & \multirow{5}{*}{$\begin{array}{l}\text { Occasional } \\
\text { platelet clump }\end{array}$} \\
\hline 4 & 78 & Renovascular disease & $\begin{array}{l}\text { Ischaemic } \\
\text { changes }\end{array}$ & & 12.8 & 238 & & \\
\hline 5 & 36 & $\begin{array}{l}\text { Hypertensive } \\
\text { nephropathy }\end{array}$ & No & & 15.7 & 196 & & \\
\hline 6 & 73 & Renovascular disease & No & $\begin{array}{l}\mathrm{L} 11.6 \mathrm{~cm} \\
\text { R } 9.3 \mathrm{~cm}\end{array}$ & 13.6 & 168 & & \\
\hline 7 & 79 & $\begin{array}{l}\text { Hypertensive } \\
\text { nephropathy }\end{array}$ & No & $\begin{array}{l}\text { L } 8.5 \mathrm{~cm} \text {, numerous small cysts } \\
\text { R } 8.7 \mathrm{~cm} \text {, numerous small cysts }\end{array}$ & 11.7 & 291 & & \\
\hline
\end{tabular}

\section{Discussion}

In this study, we have examined whether haemodialysis patients within the same vicinity as the family initially described by Warwicker et al. [2] might unknowingly carry $C F H$ c.3643C $>$ G; p.Arg1215Gly. This was pre-empted by the discovery of this change in a patient who developed post-transplant TMA, in whom the original underlying diagnosis was malignant hypertension. We specifically screened those haemodialysis patients without a primary diagnosis and those with a diagnosis of malignant hypertension or chronic glomerulonephritis (not biopsied) or renovascular disease. Seven patients met these criteria, and in none of them did we find $C F H$ c.3643C >G; p.Arg1215Gly. At the same time, we screened 4,000 healthy individuals living within the same vicinity as the family described by Warwicker et al. [2] for $C F H$ c.3643C>G; p.Arg1215Gly, and in none of them did we find this change.

Although we have not been able to categorically show that the index patient shares a common lineage to the family described by Warwicker et al. [2], we assume this to be the case. Le Quintrec et al. [8] have previously shown that $29 \%$ of patients with de novo post-transplant TMA have a mutation in either $C F H$ and/or CFI. Based on this observation, it is routine practice within the UK to screen all patients with de novo post-transplant TMA for mutations in $C F H, C F I, C D 46, C 3$ and $C F B$, and to screen for factor $\mathrm{H}$ autoantibodies. This practice led to the finding of $C F H$ c.3643C $>$ G; p.Arg1215Gly in this patient. It is interesting that his primary renal diagnosis was malignant hypertension. Both the presentation of malignant hypertension and the renal biopsy findings in this condition can be similar to aHUS. It is unfortunate that at the time of his presentation eculizumab was not available. There is now overwhelming evidence that recurrent post-transplant aHUS responds to treatment with eculizumab [9]. Both the findings of Le Quintrec et al. [8] and the observation that this patient presented with apparent de novo post-transplant TMA raise the possibility that de novo post-transplant TMA should be treated with eculizumab especially if it is resistant to plasma exchange. There are anecdotal reports supporting this $[10,11]$. Future transplantation in this patient will undoubtedly need to be undertaken under the cover of eculizumab.

The case we report here and the large number of affected/unaffected carriers of $\mathrm{CFH}$ c.3643C>G; p.Arg1215Gly in the family described by Warwicker et al. [2] also led us to examine whether this sequence variant might be detectable within the 'healthy' population in the vicinity of this family. We screened 4,000 such individuals and did not find this variant. This is in keeping with the absence of the change in any other haemodialysis patients in the region. 
Despite not finding this change in either the haemodialysis population or the local healthy population, we have a low index of suspicion for undertaking mutation screening in those patients who present with features such as malignant hypertension that might be compatible with a diagnosis of aHUS.

\section{Acknowledgements}

Samples used in this study were provided by the National Institute for Health Research (NIHR) Exeter Clinical Research Facility. This article presents independent research supported by the NIHR Exeter Clinical Research Facility. The views expressed are those of the author(s) and not necessarily those of the NHS, the NIHR or the Department of Health.

We would like to thank Professor Tim Frayling for his assistance with genotyping.

\section{Disclosure Statement}

The authors have no competing financial interests.

\section{References}

1 Edelsten AD, Tuck S: Familial haemolytic uraemic syndrome. Arch Dis Child 1978;53:255-256.

$>2$ Warwicker P, Goodship TH, Donne RL, Pirson Y, Nicholls A, Ward RM, Turnpenny P, Goodship JA: Genetic studies into inherited and sporadic hemolytic uremic syndrome. Kidney Int 1998;53:836-844.

-3 Caprioli J, Noris M, Brioschi S, Pianetti G, Castelletti F, Bettinaglio P, Mele C, Bresin E, Cassis L, Gamba S, Porrati F, Bucchioni S, Monteferrante G, Fang CJ, Liszewski MK, Kavanagh D, Atkinson JP, Remuzzi G: Genetics of HUS: the impact of MCP, CFH, and IF mutations on clinical presentation, response to treatment, and outcome. Blood 2006;108:1267-1279.

4 Kavanagh D, Goodship T: Genetics and complement in atypical HUS. Pediatr Nephrol 2010;25:2431-2442.

5 Boyer 0, Niaudet P: Hemolytic uremic syndrome: new developments in pathogenesis and treatment. Int J Nephrol 2011;2011:908407.

-6 Noris M, Caprioli J, Bresin E, Mossali C, Pianetti G, Gamba S, Daina E, Fenili C, Castelletti F, Sorosina A, Piras R, Donadelli R, Maranta R, van der Meer I, Conway EM, Zipfel PF, Goodship TH, Remuzzi G: Relative role of genetic complement abnormalities in sporadic and familial aHUS and their impact on clinical phenotype. Clin J Am Soc Nephrol 2010;5:1844-1859.

7 Moore I, Strain L, Pappworth I, Kavanagh D, Barlow PN, Herbert AP, Schmidt CQ, Staniforth SJ, Holmes LV, Ward R, Morgan L, Goodship TH, Marchbank KJ: Association of factor $\mathrm{H}$ autoantibodies with deletions of CFHR1, CFHR3, CFHR4, and with mutations in CFH, CFI, CD46, and C3 in patients with atypical hemolytic uremic syndrome. Blood 2010;115:379-387.

-8 Le Quintrec M, Lionet A, Kamar N, Karras A, Barbier S, Buchler M, Fakhouri F, Provost F, Fridman WH, Thervet E, Legendre C, Zuber J, Fremeaux-Bacchi V: Complement mutation-associated de novo thrombotic microangiopathy following kidney transplantation. Am J Transplant 2008;8:1694-1701.

-9 Zuber J, Le Quintrec M, Krid S, Bertoye C, Gueutin V, Lahoche A, Heyne N, Ardissino G, Chatelet V, Noel LH, Hourmant M, Niaudet P, Fremeaux-Bacchi V, Rondeau E, Legendre C, Loirat C: Eculizumab for atypical hemolytic uremic syndrome recurrence in renal transplantation. Am J Transplant 2012;12:3337-3354.

-10 Wilson CH, Brown AL, White SA, Goodship TH, Sheerin NS, Manas DM: Successful treatment of de novo posttransplant thrombotic microangiopathy with eculizumab. Transplantation 2011;92:e42-e43.

11 Chandran S, Baxter-Lowe L, Olson JL, Tomlanovich SJ, Webber A: Eculizumab for the treatment of de novo thrombotic microangiopathy post simultaneous pancreas-kidney transplantation - a case report. Transplant Proc 2011;43:2097-2101. 